\title{
Mongolian academic botanic garden as an introduction center and ecological resource for plant biodiversity conservation
}

\author{
Genden Ochirbat ${ }^{1 *}$, Nanjidsuren Ochgerel $^{2}$, Victor Kuzevanov ${ }^{3}$, and Luvsanbaldan \\ Enkhtuya $^{2}$ \\ ${ }^{1}$ Ulanbaatar University of Mongolia, 17024 Ulaanbaatar, Mongolia \\ ${ }^{2}$ Botanic Garden and Research Institute of the MAS, 13330 Ulaanbaatar, Mongolia \\ ${ }^{3}$ Irkutsk State University, 664003 Irkutsk, Russia
}

\begin{abstract}
The main results and achievements of the introduction work carried out at the Botanic Garden of the Mongolia Academy of Sciences (BG MAS) for almost 50 years of complicated development with ups and downs are given. It shows modern positioning and value of the BG MAS as the main country's introduction center, ecological resource and public educational organization, treasurer of the scientific knowledge for the conservation and rational use of plant genetic resources, which contributes to the growing process of new botanic gardens and nurseries formation in Mongolia.
\end{abstract}

\section{Introduction}

The harsh continental climate of Mongolia presents a lot of difficulties for the introduction of plants, the biodiversity of which is great enough for the extremal living conditions (about 3191 species of vascular plants represent native flora of Mongolia). For a variety of natural zones abounding in lakes and rivers, from the mountainous and forested region of the Khangai in the north through the vast steppes to the sandy hills of the Gobi Desert in the south of the country, extreme annual temperature fluctuations from $-56^{\circ} \mathrm{C}$ to $+50^{\circ} \mathrm{C}$ are characteristic, and daily variations could be more than $20^{\circ} \mathrm{C}$. Introduction studies of Mongolian plants are of great importance both for the preservation of certain species, endemic, rare and endangered ones as well as for the rational use of plants of economic interest. In this context, the academic Botanic Garden of the Mongolian Academy of Sciences (BG MAS) plays an increasing scientific and educational role for environmental monitoring, a nature management and for the socio-economic development [1].

\section{The objectives of the study}

\footnotetext{
* Corresponding author: ochirbat_991@yahoo.com
} 
1) to provide an overview of the accumulated research and collection materials of the BG MAS in terms of introduction work and 2) to assess its positioning as an ecological resource and a key introduction center in conditions of its revival after a long stagnation.

\section{Objects, materials and methods}

We studied collections of introduced plants in collections sites of rare, endemic, and especially economically valuable and practically useful species of the BG MAS. After complicated socio-economic transformations in the country, to date, the BG MAS has managed to retain 18 ha of fertile land on the outskirts of the city of Ulaanbaatar (having given about 14 hectares away to the city). The 8 ha is used as green public displays for botanical and environmental education of the population, while the remaining 10 hectares are used for research. Traditional introduction and field methods are used for studies and preserve the flora gene resources the BG MAS pays attention to the ex situ approaches. This creates a promising basis for reproduction and other methods of plant conservation, including propagation by seeds or vegetative propagation.

Table 1. The ratio of life forms of introduced vascular plants in the BG MAS living collections in 2021

\begin{tabular}{|c|c|c|}
\hline \multirow{2}{*}{ Parameters } & \multicolumn{2}{|c|}{ Plant collections } \\
\cline { 2 - 3 } & Trees and shrubs & Herbaceous plants \\
\hline Total number of species & $122(33 \%)$ & $248(67 \%)$ \\
\hline Rare and endangered species & 17 & 78 \\
\hline
\end{tabular}

\section{Results and discussions}

The BG MAS managed to introduce and preserve many new cultivated species and their collection plantations, thanks to the previous long-term 50-year work done by many botanists in the cultivation of rare, endemic, endangered, economically valuable and practically useful plants of the Mongolian flora, including a few species from neighboring and remote countries. The main indicator of the introduction studies of the BG is the diversity and number successfully introduced plant species. At the moment, there are quite steady living collections in ex situ conditions included 370 species $(12.0 \%$ of the total of the native flora of Mongolia), 160 genera and 60 families. 95 species $(21.5 \%)$ are rare and especially rare plants (Table 1). At present, native Mongolian plants make up the dominant basis of living collections, while introduced species from remote countries constitute about $4 \%$. These indicators are in good agreement with the global objectives of the international «Convention on Biological Diversity» and the goals of the international «Global Strategy for Plant Conservation».

More than 100 species of trees, shrubs and herbaceous plants have been identified as promising things for acclimatization, which can be used for landscaping cities and for creating productive gardens. Long-term systematic phenological studies of cultivated plants became very valuable source for keeping journals of phenological observations and creating an information database. The targeted research on the topic «Ecological and biological substantiation of the introduction of ornamental shrub plants for green urban construction» made it possible to successfully enrich flora of parks of Mongolia using 29 acclimatized ornamental shrub species (Lilac genus, etc.) from neighboring and from Europe. 
Introduction studies with ornamental herbaceous plants of the indigenous flora of Mongolia made it possible to cultivate 35 species, of which 26 species were recommended for group plantings, 18 for - curbs, and 21 - for grassy lawns. Long-term introduction trials during the cultivation of Paeonia lactiflora Pall., P. anomala L., Allium altaicum Pall., A. oblyquum L., Tulipa uniflora (L.) Bess ex Baker., Lancea tibetica Hook.et Tomas., Iris species, Lilium bushianum Lodd. and L. dauricum Ker-Gaul, as well as rare and endangered herbaceous plants allowed BG MAS to increase significantly both their number and the area of their living collections for large-scale reproduction [2, 3] (Fig. 1 and 2). For example, ontogenetic studies made it possible not only to assess the introduction potential of the most promising varieties for Mongolia, but also to organize nurseries for large-scale reproduction of seedlings from seeds.

Studies of the biological characteristics of ontogenesis and the introduction of shrubby plants of food and medicinal value in cultivation made it possible, made it possible to clarify the peculiarities of the life cycle stages of shrubs genus Spirea and species Crataegus sanguinea Pall. in order to optimize the selection of a suitable age of plant seedlings for city greenification.

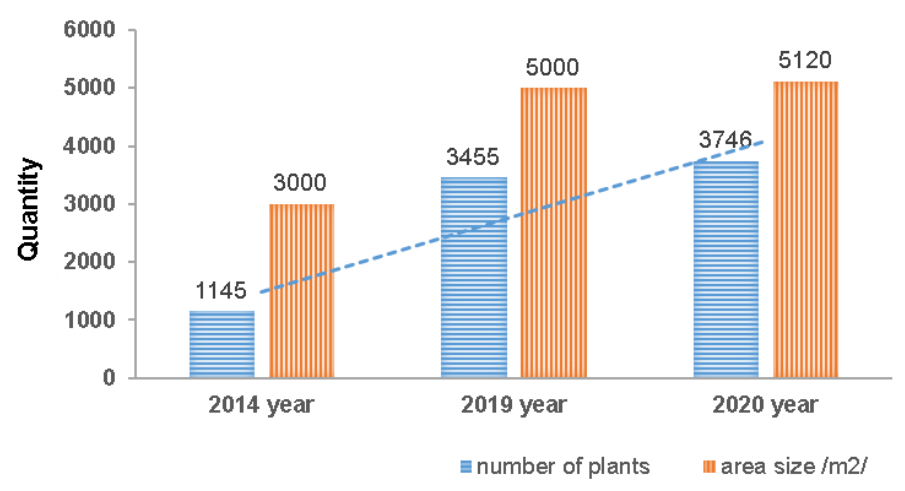

Fig. 1. Dynamics of herbaceous plants acquisition in living collections of the Botanic Garden of the Mongolian Academy of Sciences for 2014-2020, broken down by the number of plant specimens (blue) and the total land area occupied by them (orange)

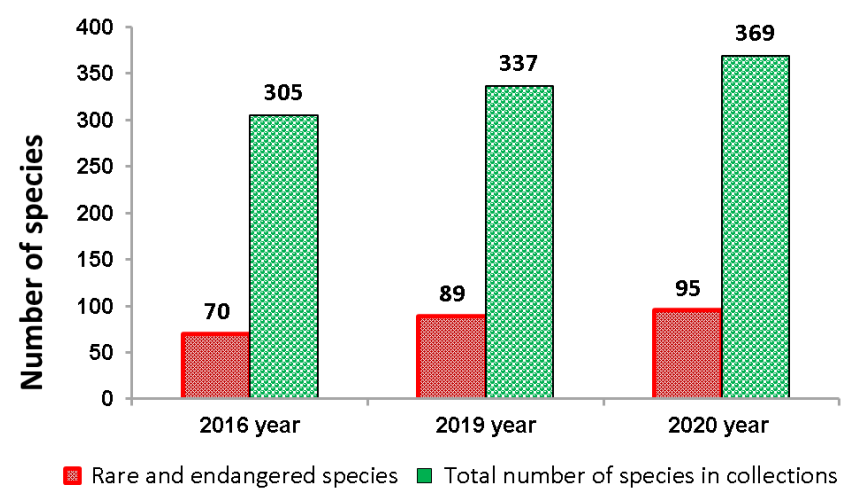

Fig. 2. Dynamics of vascular plant species acquisition in living collections of the Botanic Garden of the Mongolian Academy of Sciences for 2016-2020, broken down by the number of rare and endangered species (red) and the total number of species (green)

The BG MAS creates specialized collections of promising complexes of plant genera for introduction: Birch, Poplar, Lilac, Rose, Spirea, Iris, Peony, Allium, Lily, and others in 
the evaluation garden. Along with the traditional investigations on the theory and practice of plant introduction, the BG MAS is expanding the spectrum of non-traditional activities, including, for example, the study and introduction of rich nectar-bearing plants, the studies of the pollination features, the accumulation of essential oils, aromatic and aromatic substances, processes which emit milky exudates, various resins, physiologically active secretions and others. One of the most intriguing issues is the nectar-honey production and pollen productivity of the introduced plants, which indeed makes it possible to identify and introduce prospective species into cultivation on agricultural fields in Mongolia [4-6]. The BG MAS is functioning as an exclusive plant introduction center and botanical resource science of Mongolia dealing with the introduction of economically valuable and practically useful plants, rare and endemic species [7].

A database and information system concerning new exotic crops, trees, shrubs and herbaceous plants for greenification of cities has been created here for the assessment and selection of appropriate species, proper standards for urban planning and landscaping. In 2011-2020, the BG MAS developed about 20 horticultural and ecological standards related to urban gardening. This allows us to establish and control the technical requirement for quality standards for seedlings of ornamental trees and shrubs. Thanks to the updated standards, it became possible to use annuals and perennial flowers as new crops for urban gardening and improve landscaping by increasing the biodiversity and the number of plant species and genera used. At the same time, a scientific basis and a monitoring database were technically organized for the quantitative and qualitative improvement of the urban greening system.

On the 8 ha of the public part of the BG MAS, which is an open garden for recreation of the population, environmental education and awareness-raising is organized to acquaint visitors, tourists and children with the flora and green building. More than 18,000 trees and shrubs are grown in this part. This site is considered one of the best practices for green building in Ulaanbaatar and is planned for further development.

A special environmental public part on an area of 8 hectares was organized at the BG MAS territory for public awareness promotion, to familiarize visitors, tourists and children with the plant world and «green principles», which is an open garden for recreation of the general population. More than 18,000 trees and shrubs were planted in this part of the garden. This site is considered to be one of the best practices for green building in Ulaanbaatar and is planned for further development.

The BG MAS traditionally receives most of the exotic seedlings and seeds from the neighboring Russian Federation (from the Botanic Garden of Irkutsk State University, the Main Botanical Garden of the Russian Academy of Sciences in Moscow, etc.) and other Asian countries, since genetic resources from neighboring countries with a similar climate adjust themselves better to Mongolian conditions. Thus, the BG MAS, with its actions, experience and positioning, turns out to be the leading scientific introduction center in Mongolia.

The BG MAS also exchanges delectus and seeds with 32 related botanical organizations across the world, which allows it to expand mutually beneficial partnerships, regularly participate in international forums and international botanical networks (BGCI, EABGN, etc.). Reproduction and preservation of collections of rare and endangered, decorative, medicinal and economically significant plants for various purposes is an effective example of the protection of living genetic resources in Mongolia. It is important that, thanks to the model of the Botanical Garden of the Academy of Sciences, which embodies the useful "botanic garden idea" in recent years, additional Botanic Gardens are being organized in Mongolia in various cities. Examples of this phenomenon include the "Botanic Garden of Medicinal Plants" in Songino west of Ulaanbaatar, the Institute of Medicines of the «Monos Corporation» and the botanical nursery «Khanbogd-Oyu Tolgoi» for breeding Gobi plants. 
Along with this, a number of nurseries are also being organized according to the model of a botanic garden: at the Darkhan Institute of Plant Productivity and Agriculture, the Zaisan Educational Nursery Center at the Animal Breeding University in Ulaanbaatar, the Khovd Botanic Garden at the University of Khovd, etc. All this shows a deployment of a more extensive system of introduction and rational use of plants in Mongolia.

\section{Conclusions}

1. At the Botanic Garden of the Mongolian Academy of Sciences we have established sustainable living plant collections and at the same time preserved in $\underline{\text { ex situ }}$ conditions up to 370 species (12.0\% of the number of native flora in Mongolia) 160 genus and 60 families of indigenous flora, of which 95 species $(21.5 \%)$ are rare and especially rare plants, which are important resources for the conservation of the country's biological diversity. 2. The Academic Botanic Garden is undoubtedly becoming the main conceptual introduction center for Mongolia. 3. Introduced plants from the Botanic Garden facilitate the progress of greening the cities in Mongolia and improving the "green" assortment on a scientific basis. 4. For increasing and rational use of resources of economically significant and practically useful, endemic, rare and endangered plants in Mongolia, the main hot topic is the technologies of their large-scale reproduction, where, in addition to the traditional method, biotechnology and other progressive methods should be used. 5. The Academic Botanic Garden and other related botanical organizations, thanks to the introduction and mobilization of economically and practically significant plant species, are becoming an important factor in the socio-economic development of Mongolia.

\section{References}

1. V. Ya. Kuzevanov, G. Ochirbat, L. Enkhtuyaa, N. Ochgerel, Vestnik IRGSHA, 100 (2021)

2. N. Ochgerel, Introduction of some rare herbaceous plants of Mongolia (UB, Mongolia, 2021)

3. L. Enkhtuya, Irises of Mongolia (UB, Mongolia, 2021)

4. G. Ochirbat, P. Tserennadmid, Proc. Bot. Inst. MAS, 4 (1993)

5. G. Ochirbat, The present situation and some results of introduction works of Botanic garden of MAS, The 1st Meeting of the EABGN, 19-20 August, Kunming, China (2006)

6. P. Tserennadmid, Ecological and biological features of the introduction of ornamental shrub plants and their use in green building (UB, 1995)

7. G. Ochirbat, U. Ligaa, Tasks and perspectives of botanical resource science in Mongolia in Ecological consequences of biosphere processes in the ecotone zone of South Siberia and Central Asia, 6-10 September, Ulaanbaatar, Mongolia (2010) 